\title{
FINDING AGRICULTURAL INFORMATION AT RUTGERS LIBRARIES
}

\author{
BY IRWIN WEINTRAUB \\ Dr. Weintraub is Agriculture Resource Librarian at the \\ Library of Science and Medicine, \\ Rutgers University
}

Agricultural technology in America is advancing at a more rapid rate than ever before. Consumers and producers have benefitted greatly from hybrid crop and animal strains, labor saving equipment, improved cultural practices, animal and disease control and sanitation, and the use of natural and synthetic inputs in agricultural production systems.

Advances in biotechnology have added an additional element to the agricultural research agenda. Biotechnology involves the application of living organisms to improve, modify, or produce industrially important products or processes. It has been used for decades to produce antibiotics, enzymes, and amino acids.

Applications of genetic engineering have resulted in the development of a means to diagnose and treat certain diseases, to increase milk production in cattle, and to increase the growth rate. Genetic engineering in plants has made it possible to reduce frost damage, increase resistance to herbicides, protect against insect attack, and produce hybrids.

New Jersey farmers serve the people of the State with high quality products that are reasonably priced. Agriculture contributes millions of dollars to the New Jersey economy and employs thousands of individuals. The state's 8,300 farms cover 880,000 acres of land in one of the smallest and most urbanized states in the nation. The state's key agricultural products are vegetables, fruit and berries, meat animals, milk and dairy items, nursery, greenhouse and forest products, horses, eggs and poultry, grain and hay, and fish and seafood.

Rutgers has been involved in New Jersey agriculture since it became the land grant university of New Jersey in 1864 which resulted in the establishment of the Rutgers Scientific School with departments of agriculture, engineering, and chemistry. The New Jersey Agricultural Experiment Station (NJAES) was founded in 1880. The teaching, research, and service functions of the Scientific School and NJAES 
continued to expand until 1921 when the Scientific School became the College of Agriculture. Cook College is now the location of the College of Agriculture and New Jersey Agricultural Experiment Station (NJAES). It is the third largest College of Agriculture in the United States and a vital part of higher education in New Jersey. Cook College/NJAES, serves New Jersey agriculture through its formal educational programs, research in a variety of areas, and through the active and dynamic cooperative extension service. It offers resident instruction, research and cooperative extension programs with emphases in the food, agricultural, environmental, and life sciences. These programs are designed to solve problems and present new knowledge to the State of New Jersey, the nation, and the world. Cook/NJAES highly qualified faculty are involved in teaching, research, and scholarship, and a great diversity of instructional programs. Students have access to an array of courses and major fields of concentration in agriculture, environment, life sciences, and biotechnology. Many Cook College graduates enter graduate study in law, business, medicine, dentistry, veterinary science, and other professional disciplines.

The New Jersey Agricultural Experiment Station conducts research in production agriculture, food technology, fisheries management, aquaculture, human health and nutrition, and environmental and natural resources management. NJAES is located on Cook Campus in New Brunswick with eight field stations throughout the state. These include: Bivalve/Cape Shore for shellfish research; Tuckerton for finfish; Centerton for vegetables and nursery crops; Cream Ridge for fruits; Adelphia for agronomic and turf crops; Oswego for blueberries and cranberries; Snyder Farm for agronomic, horticultural, and sustainable agriculture research; and New Brunswick for turf and horticultural studies.

Practical information from the applied research of Cook College and the NJAES is transmitted to the "grassroots" through the highly regarded Rutgers Cooperative Extension, which has 21 county offices to serve New Jersey citizens. The Cook College Office of Continuing and Professional Education operates a comprehensive program of short courses and symposia for diverse clientele in the program areas of the college and the experiment station.

In a world of rapidly changing information and global approaches to finding answers to agricultural, environmental and health problems, easy access to information is critical for those who carry out research and 
those who apply the results in their daily work. In the past, information dissemination in the sciences was carried out mainly through printed sources. Many of the printed approaches to information retrieval are quickly becoming obsolete and being replaced by electronic innovations. Printed sources can no longer function as the major avenue for communication of agricultural knowledge. Although printed sources still remain as one of the available options, today's information seekers need the efficiency, speed and currency that is offered through electronic sources such as online information networks, CD-ROM, electronic bulletin boards, global networks and others. Local area networks and campus-wide networks are available to enhance the users' ability to find the required information.

Access to agricultural information services for Cook College is available at the Mabel Smith Douglass Library on the Douglass Campus and the Library of Science and Medicine (LSM) at Busch Campus. Douglass Library collects the basic materials used by undergraduates. The Library of Science and Medicine at Busch Campus houses the research materials that are used by graduate students, and teaching and research faculty in all the disciplines at Cook College including plant and animal sciences, marine sciences, environmental sciences, and food science and nutrition. The Entomology Library, located in J.B. Smith Hall on Cook Campus, contains a collection of basic books, periodicals and bibliographies on subjects of interest to the Department of Entomology and Economic Zoology. An Agricultural Sciences Library is now under construction at Foran Hall, the new AgBiotech and Plant/Life Sciences complex on Cook Campus. This library will open during Spring 1995 as a graduate level and research facility with electronic information retrieval capabilities, book, reference, and periodical collections and a variety of information services.

\section{Electronic and Printed Resources in Agricultural Information}

There is a great diversity of electronic and printed databases available at Rutgers to cover the agricultural information needs of most users. Some of the most popular sources are described here to present an overview of the literature searching options available to the Cook College community. 


\section{Agriculture}

AGRICOLA. A database produced by the National Agricultural Library (NAL). It contains citations to worldwide literature in every field of agriculture and related areas including all materials in the collection at NAL. About 190,000 citations are added each year covering over 5,000 periodicals, monographs, reports, government documents, bibliographies, theses, patents and other resources. Specialized information centers at NAL in alternative farming systems, food and nutrition, aquaculture, biotechnology and water quality provide additional information regularly to $A G R I C O L A$. AGRICOLA records are used to produce the printed version, Bibliography of Agriculture. AGRICOLA is available at Rutgers in online and in CD-ROM formats, and in the printed edition.

AGRIS International. A cooperative database issued by the Food and Agriculture Organization of the United Nations. This database provides references to international information in scientific, technical and socioeconomic literature relating to food, agriculture, nutrition and rural development with emphasis on developing countries. Records for AGRIS International are produced by over 130 national centers and 18 regional and international centers. Each participating country assumes responsibility for providing $A G R I S$ with appropriate bibliographic information for its publications. Nearly 2 million records are entered annually covering periodicals, monographs, reports, patents, standards, dissertations, proceedings, trade catalogs, laws and regulations and unpublished documents. Records are also provided by the National Agricultural Library (NAL) and Commonwealth Agricultural Bureau International (CABI) for those materials relevant to AGRIS subject areas. The majority of the entries are unique citations representing the literature of developing countries. Available online at Rutgers.

Biological and Agricultural Index. A cumulated subject index to literature of agricultural and biological sciences from over 200 international periodicals in English. It contains over 4,000 citations per month; 45\% of subject coverage is in agriculture. Subjects such as biochemistry, environmental sciences, ecology, microbiology and nutrition are given extensive coverage. Cumulated quarterly and annually. Online, CDROM and printed editions are available at Rutgers.

$C A B$ International ( $C A B I)$. This database is produced by the Commonwealth Agricultural Bureau International in the United Kingdom. It offers a computerized bibliographic database of research literature on all aspects of agriculture, veterinary and forestry sciences and related 
disciplines including applied biology, biotechnology, crop protection, economics and sociology. $C A B I$ consists of 11 bureaus that scan the relevant scientific and technical literature from over 14,000 serials and 5,000 other publications from over 130 countries including books, chapters of books, conference proceedings, reports, patents, national and international standards and theses. Grey literature is included when possible. The online version contains nearly 3 million records back to 1973 that may be searched in its entirety or limited to particular subfiles or subfile combinations. Available online at Rutgers. Printed abstracting journals have been produced from the $C A B$ International database since 1973 in animal science and production, veterinary science and parasitic diseases, crop science and production, forestry, crop protection, economics, development and sociology, machinery and buildings, human nutrition, and biotechnology and biodeterioration. Titles available at Rutgers in printed editions are: AgBiotech News and Information, Apicultural Abstracts, Forest Products Abstracts, Forestry Abstracts, Helminthological Abstracts, Nematological Abstracts, Horticultural Abstracts, Index Veterinarius, Nutrition Abstracts and Reviews, Plant Breeding Abstracts, Review of Agricultural Entomology, Review of Medical and Veterinary Entomology, Review of Medical and Veterinary Mycology, Review of Plant Pathology, Soils and Fertilizers, Veterinary Bulletin, Weed Abstracts, World Agricultural Economics and Rural Sociology Abstracts. The journals appear monthly or quarterly with subject and author indexes in each issue and annual cumulated indexes.

CRIS (Current Research Information System). The Current Research Information System of the USDA is a computer-produced reporting system for new, ongoing and recently completed publicly supported research in agriculture, forestry, and related fields in the United States. Descriptions of over 30,000 research projects conducted by the USDA, state agricultural experiment stations, land grant universities, state forestry schools and cooperating schools of veterinary medicine are entered yearly. Information on human nutrition research projects by various government agencies are included in the HNRIMS subfile. Terminated projects remain in the file about three to four years and are purged annually. New projects are added monthly. Project descriptions include a brief summary, progress reports and citations to publications not yet cited elsewhere. Available online at Rutgers. 


\section{Biological Sciences}

BIOSIS Previews. BIOSIS Previews is the computer readable version of Biological Abstracts and Biological Abstracts/RRM (Reports, Reviewes and Meetings). It cites journal articles, monographs, proceedings of meetings, conferences and symposia, reports, short communications, notes and reviews in the biological sciences including animal and plant sciences, interdisciplinary fields and related areas. The database covers about 9,000 serials from over 100 countries in more than 80 languages. Nearly 535,000 records are added to the database each year. Searches can be carried out using titles, keywords, concept codes, biosystematic codes and text from the abstracts. An accompanying search guide lists codes, vocabulary terms, scope notes, glossary and index to assist in designing effective searches. Available online at Rutgers and in printed editions as Biological Abstracts and Biological Abstracts/RRM.

\section{Sustainable Agriculture}

Abstreco: Abstracts on Sustainable Agriculture. An international abstracting service covering journal articles, reports, books and other relevant publications in sustainable agriculture. References are derived from the documentary input of Agralin, the database of the Wageningen Agricultural University in 'The Netherlands. Arranged by subject covering all aspects of sustainable agriculture including production, management, marketing, nutrition, pest control as well as the philosophy and sociological aspects of sustainable agriculture. Available in printed editions at Rutgers.

Abstracts on Sustainable Agriculture. Published annually in English by Deutsches Zentrum für Entwicklungstechnologien, Eschborn, Germany. Comprehensive coverage of world literature in sustainable agriculture from journals, books, reports, government documents, conferences, and other sources. Cites literature covering the ecological, socioeconomic, or locational aspects of the topic. Arranged by subject under farming systems, agroecology, home gardens, seed production, erosion control, and soil, plant and water management. Available in printed editions at Rutgers.

\section{Tropical Agriculture}

Abstracts on Tropical Agriculture. Published in Amsterdam by the Royal Tropical Institute. An abstracting journal citing about 4,000 references per month from world literature on cultivation of food and industrial 
crops, forage and pastures, agroforestry, post-harvest operations, farming systems and environmental management in tropical and subtropical regions. Review articles on relevant subjects are included at irregular intervals. Arranged by subject under 17 main topics with complete bibliographic information including language and key words. Subject index, geographical index and plant taxonomic name index in each issue. Available online and printed editions at Rutgers.

\section{Environmental Sciences}

Environment Abstracts. Abstracts of literature addressing the impact of humankind and technology on the environment. Emphasizes air, water, and noise pollution, solid and toxic wastes, radiological contamination, toxicological effects, control technologies, resource management, population, endangered species and geophysical and climatic change. Includes environmental issues in agriculture and forestry. Covers journals, conference proceedings, newsletters, and reports from academic, corporate, and government sources. Citations preceded by an asterisk $\left({ }^{*}\right)$ are available in microfiche at Douglass Library. Cumulated annually as Environment Abstracts Annual. Available online and printed editions at Rutgers.

Pollution Abstracts. Abstracts of over 2,500 citations annually to world literature on all aspects of environmental pollution. Covers air pollution, marine and freshwater pollution, sewage and wastewater treatment, waste management, toxicology and health, noise pollution, radiation, land pollution, and environmental policies, programs, legislation and education. Includes all aspects of agricultural pollution from fertilizers, pesticides, herbicides, wastes, runoff, leaching and other aspects. Cites journal articles, conference proceedings, books, government documents and special documents with limited circulation. Available online and in printed editions at Rutgers.

\section{Food Science and Nutrition}

Food Science and Technology Abstracts. A monthly abstracting service covering literature on the scientific and technical aspects of foods, food processing and food handling in more than 2,000 journals in 40 languages. Also cites patents, books, conference proceedings and legislative papers. Available online and printed editions at Rutgers.

Nutrition Abstracts and Reviews: Series A - Human and Experimental. Covers worldwide literature in human nutrition with sections on analytic techniques, foods, physiology and biochemistry, nutrition and 
health, disease, and therapeutic nutrition. Available online via $C A B$ International and in printed editions at Rutgers.

Nutrition Abstracts and Reviews: Series B - Livestock Feeds and Feeding. Cites worldwide literature on all aspects of livestock nutrition. Includes sections on analytic techniques, technology, feedstuff and feeds, physiology, biochemistry, feeding of animals, and diet and disease. Available online via $C A B$ International and printed editions at Rutgers.

\section{Government Documents}

Government Reports Announcements and Index. This bimonthly abstracting source is produced by the National Technical Information Service (NTIS), Springfield, Virginia. A comprehensive source for all unclassified U.S. and foreign government sponsored research available for public distribution. Cites about 60,000 reports annually in over 3,000 subject areas. Includes research reports in conventional and sustainable agriculture. Each citation gives full bibliographic information, order number, price and abstract. Keyword, personal author, corporate author, contract/grant number and NTIS order number in each issue and annual cumulations. Cited materials are available from NTIS in microfiche, paper, magnetic tape or floppy diskettes. Available online and printed editions at Rutgers.

Monthly Catalog of U.S. Government Publications. Issued by Superintendent of Documents, U.S. Government Printing Office, Washington, DC. A monthly bibliography of publications issued by all agencies and branches of the United States Government. Arranged by agency with Superintendent of Documents classification number (SuDocs Number), full bibliographic information and designation for depository materials. Entries are arranged by issuing agencies. Includes materials issued by the U.S. Department of Agriculture and other agencies on topics related to agriculture. Each issue includes list of special materials, list of government authors, list of Federal depository libraries, instructions for ordering publications, and author, title, subject, series/report number, contract number, stock number and title keyword indexes. Annual periodical supplement covers government publications issued three or more times a year. Available in printed, online and CD-ROM editions at Rutgers. 


\section{Aquaculture and Fisheries}

Aquatic Sciences and Fisheries Abstracts. A comprehensive abstracting service citing about 5,000 serials and books, reports, conference proceedings, translations and special publications in all aspects of aquatic sciences and fisheries. This source is issued in three parts covering biological and ecological aspects of marine, brackish and freshwater environments, physical and chemical oceanography and limnology, marine geophysics and geochemistry, marine technology, ocean policy and non-living resources, and all aspects of pollution and environmental quality related to aquatic environments. Available online and printed editions at Rutgers.

Fisheries Review. A guide to literature on all aspects of fish raising and management. Covers culture and propagation, limnology and oceanography, morphology, physiology, genetics and behavior, natural history, parasites and diseases, pollution and toxicology, and research and management. Available in printed editions at Rutgers.

\section{Citation and Current Awareness Indexes}

Science Citation Index. A multidisciplinary index covering world periodical literature in the sciences from over 5,000 journals. The purpose of this index is to enable users to find out which papers in their disciplines are being cited by other authors. Includes access by citation (cited author), source (citing author), corporate (address of citing author), and permuterm subject (subjects of articles of citing author) indexes. Available online and printed editions at Rutgers.

Index to Scientific and Technical Proceedings. Index to tables of contents of published papers presented at scientific and technical conferences, seminars, symposia, colloquia, conventions and workshops. Access is provided through category, author/editor, sponsor, meeting location, geographic and organization indexes. Available online and printed editions at Rutgers.

Current Contents: Agriculture, Biology and Environmental Sciences. A weekly listing of the tables of contents of over 900 journals and books in agriculture and related sciences. Available online and printed editions at Rutgers.

Current Contents: Life Sciences. Weekly listing of the tables of contents of over 1,200 journals and books in the life sciences. Available online and printed editions at Rutgers 


\section{Electronic Resources}

Patrons at Rutgers may use a variety electronic information services in addition to online and CD-ROM approaches. The major advantage of electronic access is to make information available to a wide audience by removing it from the confines of the library building. With a personal computer, a modem and appropriate communication software, a user can receive and send information to and from a site at any time or place. Electronic catalogs and cooperative databases are available to identify materials held in the Rutgers Libraries and in catalogs and collections elsewhere in the United States and the world. These services also provide general reference information and some databases. These electronic resources can be useful for those who need basic information on a topic. They may be used to update a bibliography, to keep informed about titles of new publications, for compiling reading lists on a topic or for browsing. Some users start with electronic services at the beginning of a search to gain a perspective on what is available. Faculty, staff and students with accounts on the University network can access the following catalogs and services at no cost on their personal computers at any location or at special terminals in the libraries.

IRIS. The Rutgers University online catalog, IRIS (Integrated Rutgers Information System), identifies cataloged materials held by all Rutgers Libraries in New Brunswick, Camden and Newark. IRIS currently contains over 810,000 bibliographic records representing 1.5 million items in 21 libraries that have been cataloged since 1975. Older materials are slowly being added and eventually all card catalogs will be eliminated. Users can search by author, title or subject to locate books, journals, reports or other materials which have been cataloged and added to the collections at the Rutgers Libraries. Searching can also be limited by location, date, language, or type of materials. To improve search precision, the Boolean option can be used. Boolean options make it possible to combine words in author, title or subject indexes using AND, OR and NOT commands.

$I N F O$. INFO is an online information system available to members of the Rutgers community. It contains general information about Rutgers University, faculty and student directories, reference materials including dictionaries, quotations, various Bibles, services such as weather and special software for retrieving information from databases and other sites outside Rutgers. By choosing "Library-Menu" on the INFO menu screen, users have access to IRIS and RLIN. Through the Internet option 
on the INFO screen, users can search online catalogs of scores of other institutions around the country. Users who are doing comprehensive searches in their fields of interest rely on the INFO options to supplement their searches. One of the most popular databases on INFO is UnCover. UnCover contains the tables of contents of over 10,000 journals. This database is produced by the Colorado Alliance of Research Libraries and contains citations for over 1,800,000 articles which have appeared since fall 1988 . Information is entered into UnCover every day as periodical issues are received in the Colorado research libraries. The journals cited in the database cover all disciplines in science, social sciences and humanities. Since UnCover is kept up to date with daily entries, it serves as an excellent current awareness service for those who need to keep up to date on the literature of agriculture.

RLIN. The Research Libraries Information Network (RLIN) is a cooperative database containing the holdings of over 124 major research libraries in the United States and abroad. Participating libraries enter their holdings in RLIN with full bibliographic information. Searches can be carried out by author, title, or subject words or combinations of these fields. The National Agricultural Library, U.S. Government Printing Office and other government agencies and academic institutions participate in this effort. With a modem and an account on the University network, users can access $R L I N$ at their home or office computers. $R L I N$ is used by patrons to verify bibliographic information and to find out if the desired material can be located at other sites for interlibrary loan borrowing. $R L I N$ is a valuable source for finding materials in agriculture which may have been missed during searches in the standard abstracting and indexing sources. In addition, indexes and abstracts covering newspapers, and periodicals and specialized databases such as history of science and architecture are available through RLIN.

Internet. Internet is an electronic network which connects thousands of campus, state, regional, national, and international networks around the world. A user on Internet can access library catalogs, data archives, specialized databases, discussion groups, computer conferences, campus wide information systems, and electronic mail. Remote login lets a user connect to a computer at a remote location and to interact with that computer as if it were directly connected. Internet provides three major services:

1. Sending and receiving electronic mail including electronic conferences and news groups in specific subject areas. 2. Logging on to a remote computer such as library catalogs and specialized databases. 
3. Anonymously transferring files such as documents and software to and from remote locations.

Agricultural resources on Internet are quite extensive. For example, one can find market news from the USDA, water quality information from Purdue, research results from the Agricultural Research Service of the USDA, cooperative extension bulletin boards from various states, discussion groups in dairy science, beekeeping, aquaculture, and many other resources for communicating with the agricultural community.

The range of possibilities for electronic dissemination of information are increasing every day. As new technologies are developed and existing technologies are improved, new and exciting possibilities such as enhanced graphics and voice dissemination will be widely available. 